Supporting Information for

\title{
Evolution of Dissolved Organic Matter Composition along the upper Mekong (Lancang) River
}

Ting Liu ${ }^{1}$, Xin Wang ${ }^{1,2}$, Erxiong Zhu ${ }^{1,2}$, Zongguang Liu ${ }^{1,2}$, Xinying Zhang ${ }^{1,2}$, Jingjing Guo ${ }^{1}$, Xiaoqing Liu ${ }^{1,2}$, Chen He ${ }^{3}$, Shengjie Hou ${ }^{4}$, Pingqing $\mathrm{Fu}^{5}$, Quan Shi ${ }^{3}$, Xiaojuan Feng ${ }^{1,2 *}$

${ }^{1}$ State Key Laboratory of Vegetation and Environmental Change, Institute of Botany, Chinese Academy of Sciences, Beijing, China

${ }^{2}$ University of Chinese Academy of Sciences, Beijing 100049, China

${ }^{3}$ State Key Laboratory of Heavy Oil Processing, China University of Petroleum, Beijing, China ${ }^{4}$ State Key Laboratory of Atmospheric Boundary Layer Physics and Atmospheric Chemistry, Institute of Atmospheric Physics, Chinese Academy of Sciences, Beijing 100029, China.

${ }^{5}$ Institute of Surface-Earth System Science, Tianjin University, Tianjin 300072, China

*Corresponding author: Xiaojuan Feng (xfeng@ibcas.ac.cn)

\section{Contents of this file}

Text S1 to S2

Tables $\mathrm{S} 1$ to $\mathrm{S} 2$

Figures $\mathrm{S} 1$ to $\mathrm{S} 8$

\section{Introduction}

The supporting information contains Text S1-S2, Tables S1-S2 and Figures S1-S8. Text S1 describes the quality control on dissolved lignin phenol analysis. Text S2 describes details on batch sorption experiments. Table S1 shows basic parameters of cascade reservoirs in the Lancang River. Table S2 provides the number and relative intensity of molecular formulas and characteristics detected in the dry-season samples by FTICR-MS. Figure S1 shows changes in the mean monthly air temperature and precipitation with elevation along the Lancang River. Figure S2 shows changes in DOC and lignin phenol ratios extracted by two consecutive C18 SPE cartridges from water samples in preliminary experiments. Figure S3 shows changes in the acid-to-aldehyde ratios and proportion of lignin phenols after the sorption of plant-derived 
DOM to different minerals. Figure S4 shows the relationships between DOC and monthly precipitation, between DOC and $\delta^{13} \mathrm{C}-\mathrm{DOC}$, between DOC and DOC/DON ratio, between $\Lambda_{\text {lignin }}$ and monthly precipitation, between $\Lambda_{\text {lignin }}$ and $\delta^{13} \mathrm{C}-\mathrm{DOC}$, and between $\Lambda_{\text {lignin }}$ and DOC/DON ratio, respectively. Figure S5 shows the changes in $\Sigma_{\text {lignin }}$ in the Lancang, and the relationships between $\mathrm{S} / \mathrm{V}$ and $\mathrm{C} / \mathrm{V}$, between $\Lambda_{\text {lignin }}$ and $(\mathrm{Ad} / \mathrm{Al}) \mathrm{v}$, between $\Lambda_{\text {lignin }}$ and $(\mathrm{Ad} / \mathrm{Al}) \mathrm{v}$, respectively. Figure S6 shows changes in the biological index (BIX) of DOM in the dry season. Figure S7 shows the van Krevelen diagrams on the variations of DOM molecular composition with shrub coverage, cropland coverage, and monthly precipitation, respectively. Figure S8 shows changes in the ratios of $\mathrm{C} / \mathrm{V}$ and $\mathrm{S} / \mathrm{V}$ after the sorption of grass-derived DOM to minerals under different $\mathrm{pH}$ and TSS conditions.

\section{Text S1. Quality control on dissolved lignin phenols}

For quality control, a known amount of archived sediments from Lake Washington (representing $\sim 10 \mathrm{mg}$ OC) that have been extensively characterized previously ${ }^{1}$ was used as a reference material and analyzed in the same manner in this study. The $\mathrm{Ad} / \mathrm{Al}$ ratios of $\mathrm{V}$ and $\mathrm{S}$ phenols were $0.51 \pm 0.09$ and $0.30 \pm 0.06(n=5)$, respectively, based on the analysis in our laboratory, showing no statistical difference from the values determined previously (i.e., 0.42 \pm 0.03 and $0.34 \pm 0.03$, respectively) ${ }^{1}$.

To verify that DOM was not overloaded on C18 cartridges in this study, river samples containing the same amount of DOC as the Lancang samples (i.e., $10 \mathrm{~L}$ of samples with DOC concentrations of $1.1 \mathrm{mg} \mathrm{L}^{-1}$ ) were pretreated using the same procedures as Lancang river water, passed through two C18 cartridges consecutively, and eluted with methanol. A quantitative aliquot of the methanol extracts was dried at $50^{\circ} \mathrm{C}$, re-dissolved in Milli-Q water, and measured for DOC to calculate SPE extraction efficiency as the ratio of the extracted DOC to total DOC loaded onto cartridges. The above measurements were conducted on C18 cartridges of different sizes (including 1-g, 2-g and 10-g cartridges) and duplicated for the 1-g cartridge. The extraction efficiency for the first C18 cartridge (29.6-41.7\%) fell within the acceptable range (32-45\%) previously reported. ${ }^{2}$ Only a trace amount of OC ( $\left.\sim 0.33 \mathrm{mg}\right)$ was recovered from the second C18 cartridge (extraction efficiency of 3\%; Figure S2), indicating that DOM was vastly captured by the first cartridge (i.e., no significant breakthrough of DOM from the first one). Moreover, lignin-phenol Ad/Al ratios were similar for all samples loaded on different-sized $\mathrm{C} 18$ cartridges (Figure S2). Both the extraction efficiency and $\mathrm{Ad} / \mathrm{Al}$ ratios showed high reproducibility for the 1 -g C18 cartridge. We are hence confident in the robustness of our lignin phenol analysis. 


\section{Text S2. Pretreatment of batch sorption experiments}

To prepare Poaceae extracts, the aboveground tissues of Poaceae were collected in the fall, oven-dried $\left(60^{\circ} \mathrm{C}\right)$ for $24 \mathrm{~h}$, ground $(<300 \mu \mathrm{m})$, extracted (by mixing $10 \mathrm{~g}$ litter in $750 \mathrm{ml}$ Milli-Q water at $5^{\circ} \mathrm{C}$ to avoid degradation during extraction), filtered $(0.2 \mu \mathrm{m})$ and diluted. To prepare soil minerals, soils were freeze dried, sieved $(<105 \mu \mathrm{m})$, pretreated twice with $6 \%$ $\mathrm{NaOCl}$ (bleach, adjusted to $\mathrm{pH}=8$ to minimize mineral alteration) for $18 \mathrm{~h}$ to remove lignin phenols, rinsed (six 2-h rinses with carbon-free water, four 2-h rinses with a $\mathrm{CaCl}_{2}$ solution to equilibrate the soil surfaces with calcium, and 4-6 times with carbon-free water until conductivity $<20-25 \mu \mathrm{S} / \mathrm{cm}$ ), and finally freeze dried again.

To verify our sorption results in comparison with Hernes and colleagues, ${ }^{3,4}$ another set of batch experiments containing oak (Quercus L.) leaf and Poaceae water extracts was conducted respectively with three pure minerals (kaolinite, goethite and bentonite) at $\mathrm{pH} 6.0$ and a TSS concentration of $12.5 \mathrm{~g} \mathrm{~L}^{-1}$. Consistent with previous results, ${ }^{3}$ ratios of $(\mathrm{Ad} / \mathrm{Al})_{\mathrm{V}}$ and $(\mathrm{Ad} / \mathrm{Al})_{\mathrm{S}}$ increased in the non-sorbed supernatant after mineral sorption relative to the original oak-leaf DOM (Figures S3a-b), accompanied by varying amount of irreversibly sorbed lignin phenols (Figure S3c). These results validated our sorption experiments. 
Table S1. Basic parameters of cascade reservoirs in this study.

\begin{tabular}{|c|c|c|c|c|c|c|c|}
\hline Dam & $\begin{array}{c}\text { Mean } \\
\text { inflowing } \\
\text { discharge }^{[1]}\end{array}$ & $\begin{array}{c}\text { Storage } \\
\text { capacity } \\
\text { of } \\
\text { reservoir }^{[1]}\end{array}$ & $\begin{array}{c}\text { Mean } \\
\text { water } \\
\text { depth }^{[1]}\end{array}$ & $\begin{array}{c}\text { Water } \\
\text { residence } \\
\text { time }^{2]}\end{array}$ & $\begin{array}{c}\text { Dry- } \\
\text { season } \\
\text { TSS }^{[3]}\end{array}$ & $\begin{array}{c}\text { Wet- } \\
\text { season } \\
\text { TSS }^{[3]}\end{array}$ & $\begin{array}{l}\text { mean } \\
\text { TSS } \\
\text { size }^{[4]}\end{array}$ \\
\hline & $\left(\mathrm{m}^{3} \mathrm{~s}^{-1}\right)$ & $\left(\times 10^{8} \mathrm{~m}^{3}\right)$ & (m) & (days) & \multicolumn{2}{|c|}{$\left(\mathrm{mg} \mathrm{L}^{-1}\right)$} & $(\mu \mathrm{m})$ \\
\hline Gongguoqiao (JZ) & 985 & 5.1 & 77 & 6 & 26 & 969 & 10.3 \\
\hline Xiaowan & 1210 & 151.32 & 248 & 145 & n.a. & n.a. & \\
\hline Manwan (GJ) & 1230 & 10.06 & 99 & 9 & 4 & 6 & 8.9 \\
\hline Dachaoshan & 1330 & 9.4 & 80 & 8 & n.a. & n.a. & \\
\hline Nuozhadu & 1730 & 237.03 & 205 & 159 & n.a. & n.a. & \\
\hline Jinghong & 1840 & 11.39 & 67 & 7 & n.a. & n.a. & 14.5 \\
\hline Ganlanba (GLB) & 1880 & 0.313 & 10 & 0 & 6 & 10 & \\
\hline Mengsong & 2020 & & 28 & & n.a. & n.a. & 15.2 \\
\hline
\end{tabular}


Table S2. The number and relative intensity of molecular formulas and characteristics in the dissolved organic matter (DOM) from the Lancang River during the dry season (bond values indicate samples from cascade reservoirs).

\begin{tabular}{|c|c|c|c|c|c|c|c|c|c|c|c|}
\hline \multirow{2}{*}{$\begin{array}{l}\text { Site } \\
\text { name }\end{array}$} & $\begin{array}{l}\text { All } \\
\text { peaks }\end{array}$ & $\mathrm{CHO}$ & $\mathrm{CHON}$ & CHOS & $\begin{array}{l}\text { Low-oxygen } \\
\text { HUCs }\end{array}$ & $\begin{array}{l}\text { High-oxygen } \\
\text { HUCs }\end{array}$ & Peptides & PCAs & Polyphenols & UACs & $\mathrm{SCs}$ \\
\hline & \multicolumn{6}{|c|}{ Number (proportion) of molecular formulas } & \multicolumn{5}{|c|}{ Relative intensity (\%) } \\
\hline$\overline{\mathrm{NQ}}$ & 3661 & $1977(54 \%)$ & $1276(35 \%)$ & $408(11 \%)$ & 26.8 & 49.8 & 0.6 & 2.3 & 12.5 & 8.0 & 0 \\
\hline ZQ & 2835 & $1666(59 \%)$ & $901(32 \%)$ & $268(9 \%)$ & 29.0 & 48.9 & 0.4 & 1.9 & 11.2 & 8.6 & 0 \\
\hline CD & 2729 & $1225(45 \%)$ & $1045(38 \%)$ & $459(17 \%)$ & 26.8 & 47.4 & 0.2 & 3.7 & 14.3 & 7.6 & 0 \\
\hline $\mathrm{RM}$ & 3270 & $1803(55 \%)$ & $1158(35 \%)$ & $309(9 \%)$ & 31.3 & 48.2 & 0.6 & 1.7 & 10.8 & 7.4 & 0 \\
\hline DQ & 3366 & $1770(53 \%)$ & $1216(36 \%)$ & $380(11 \%)$ & 30.2 & 47.2 & 0.2 & 2.9 & 13.2 & 6.3 & 0.1 \\
\hline $\mathbf{J Z}$ & 2767 & $1739(63 \%)$ & $817(30 \%)$ & $211(8 \%)$ & 34.2 & 49.4 & 0.4 & 1.3 & 10.6 & 4.0 & $\mathbf{0}$ \\
\hline GJ & 3852 & $2005(52 \%)$ & $1338(35 \%)$ & $509(13 \%)$ & 30.0 & 50.3 & 0.1 & 2.1 & 11.8 & 5.7 & $\mathbf{0}$ \\
\hline GLB & 2978 & $1723(58 \%)$ & $932(31 \%)$ & $323(11 \%)$ & 35.5 & 46.4 & 0.4 & 1.4 & 10 & 6.4 & $\mathbf{0}$ \\
\hline $\mathrm{AQ}^{[1]}$ & 3168 & $1719(54 \%)$ & $1085(34 \%)$ & $364(11 \%)$ & 30.0 & 49.3 & 0.6 & 2.0 & 11.3 & 6.9 & 0 \\
\hline
\end{tabular}

${ }^{[1]} \mathrm{AQ}$ is a small tributary, while the other sites are on the mainstream.

CHON, nitrogen-containing formulas; CHOS, sulfur-containing formulas; HUCs, highly unsaturated compounds; PCAs, polycyclic aromatics; UACs, unsaturated aliphatic compounds; SCs, saturated compounds. 


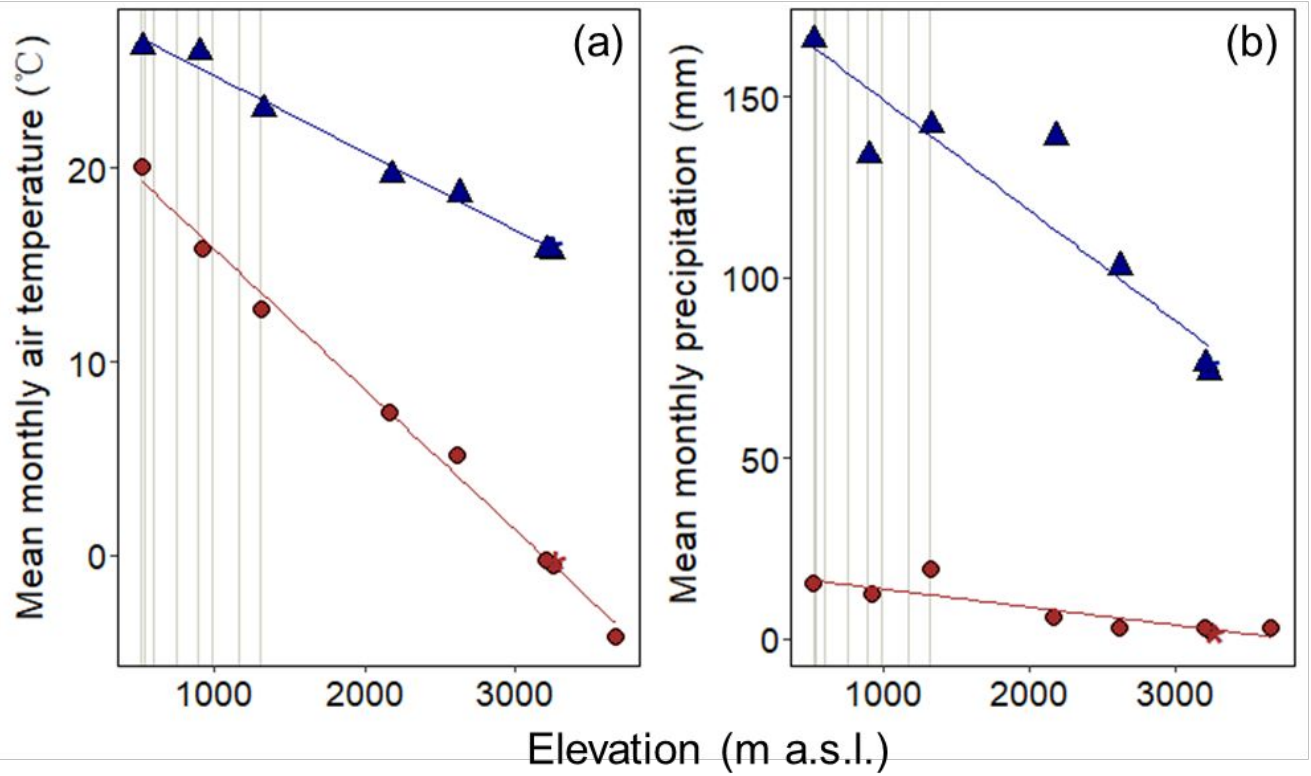

Figure S1. Changes in the mean monthly air temperature (a) and precipitation (b) with elevation along the Lancang River. Dots, triangles and asterisks represent dry-mainstem, wetmainstem and tributary samples, respectively. Dry- and wet-season samples are in red and blue, respectively. The blue and red lines correspond to the linear regression of data $(p<0.05)$, respectively. Vertical gray lines represent location of hydropower stations. 

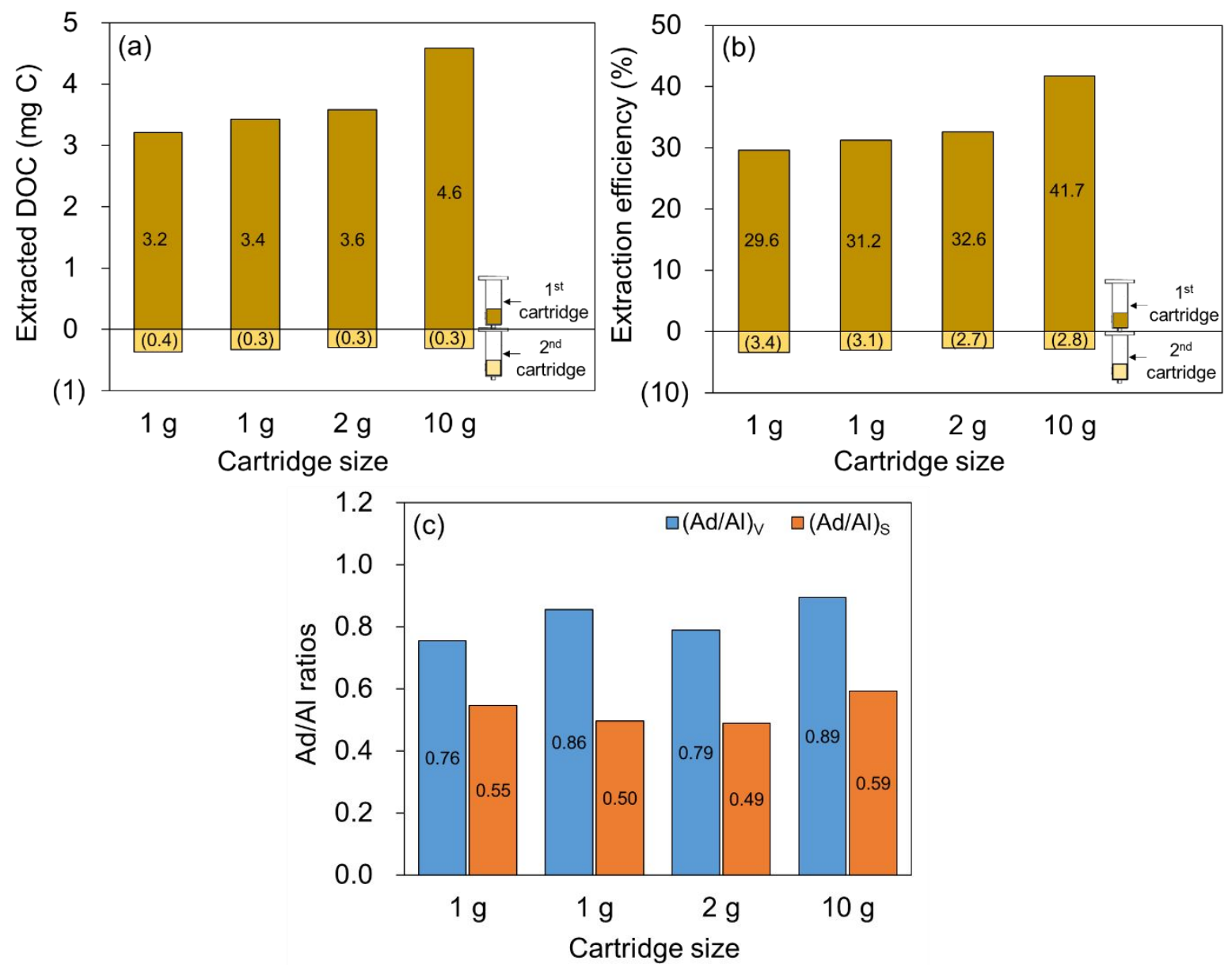

Figure S2. Changes in dissolved organic carbon (DOC) and lignin phenol ratios extracted by two consecutive $\mathrm{C} 18$ solid phase extraction (SPE) cartridges from water samples in preliminary experiments: (a) extracted DOC; (b) extraction efficiency relative to loaded DOC; (c) acid-to-aldehyde $(\mathrm{Ad} / \mathrm{Al})$ ratios of lignin phenols recovered from the first cartridge. Numbers on columns in panels represent values of the respective parameters. Numbers within parenthesis in (a) and (b) represent values for the second cartridge. 

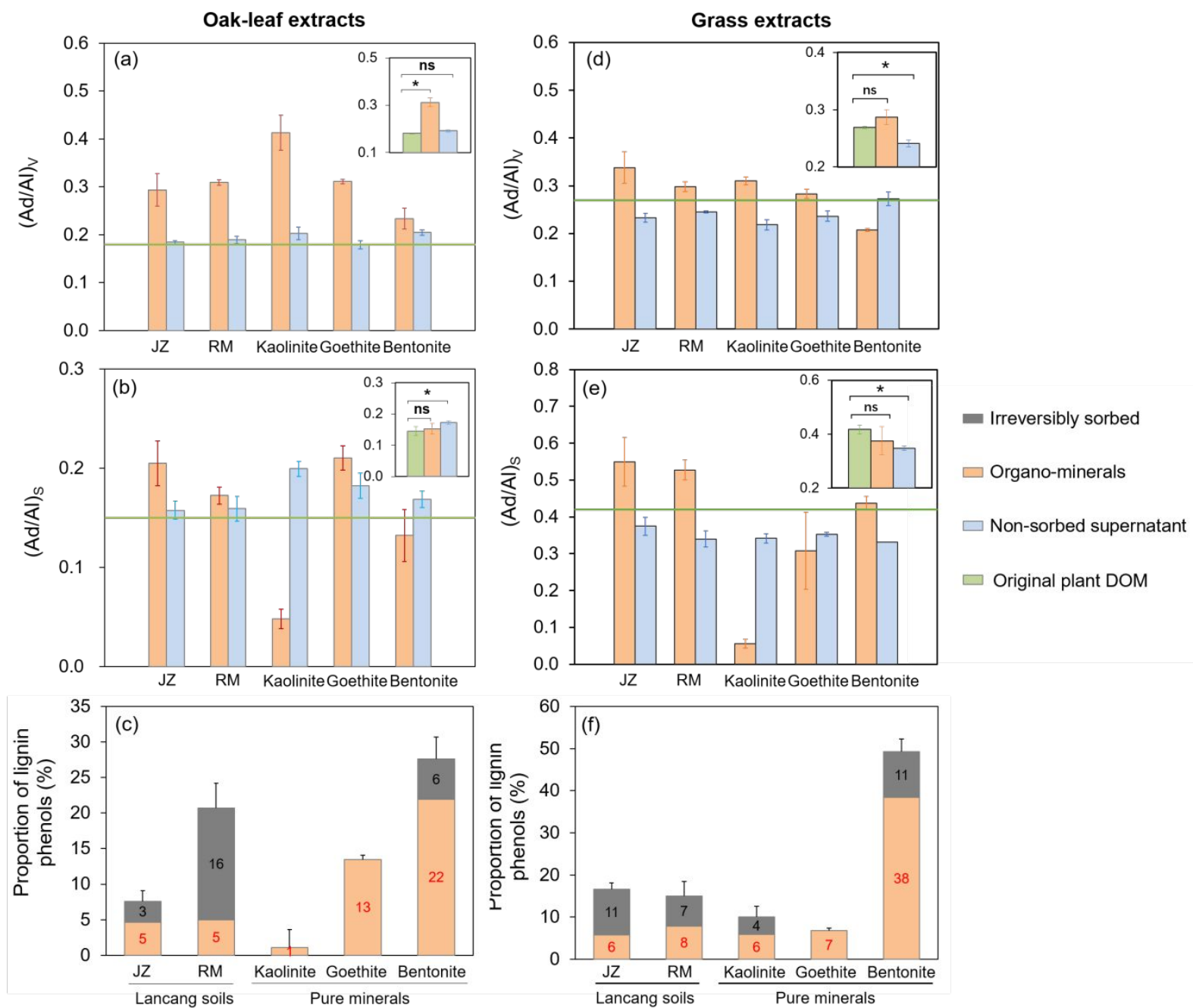

Figure S3. Changes in the acid-to-aldehyde ratios and proportion of lignin phenols after the sorption of oak-leaf-derived (a-c) and grass-derived (d-e) dissolved organic matter (DOM) to different minerals. $(\mathrm{a}, \mathrm{d})$ ratio of vanillic acid to vanillin, $(\mathrm{Ad} / \mathrm{Al})_{\mathrm{V}} ;(\mathrm{b}, \mathrm{e})$ ratio of syringic acid to syringaldehyde, $(\mathrm{Ad} / \mathrm{Al})_{\mathrm{S}} ;(\mathrm{c}, \mathrm{f})$ proportion of lignin phenols in different fractions. Green lines represent mean ratios of the original plant DOM. Error bars represent standard error of mean ( $n=3$ except in inserts). The inserts in $(a-b)$ and $(d-e)$ show mean values for all minerals $(\mathrm{n}=15)$ and respective plant extracts $(\mathrm{n}=3)$; ns, not significant; * indicates significant difference (one-way ANOVA, $p<0.05$ ). 

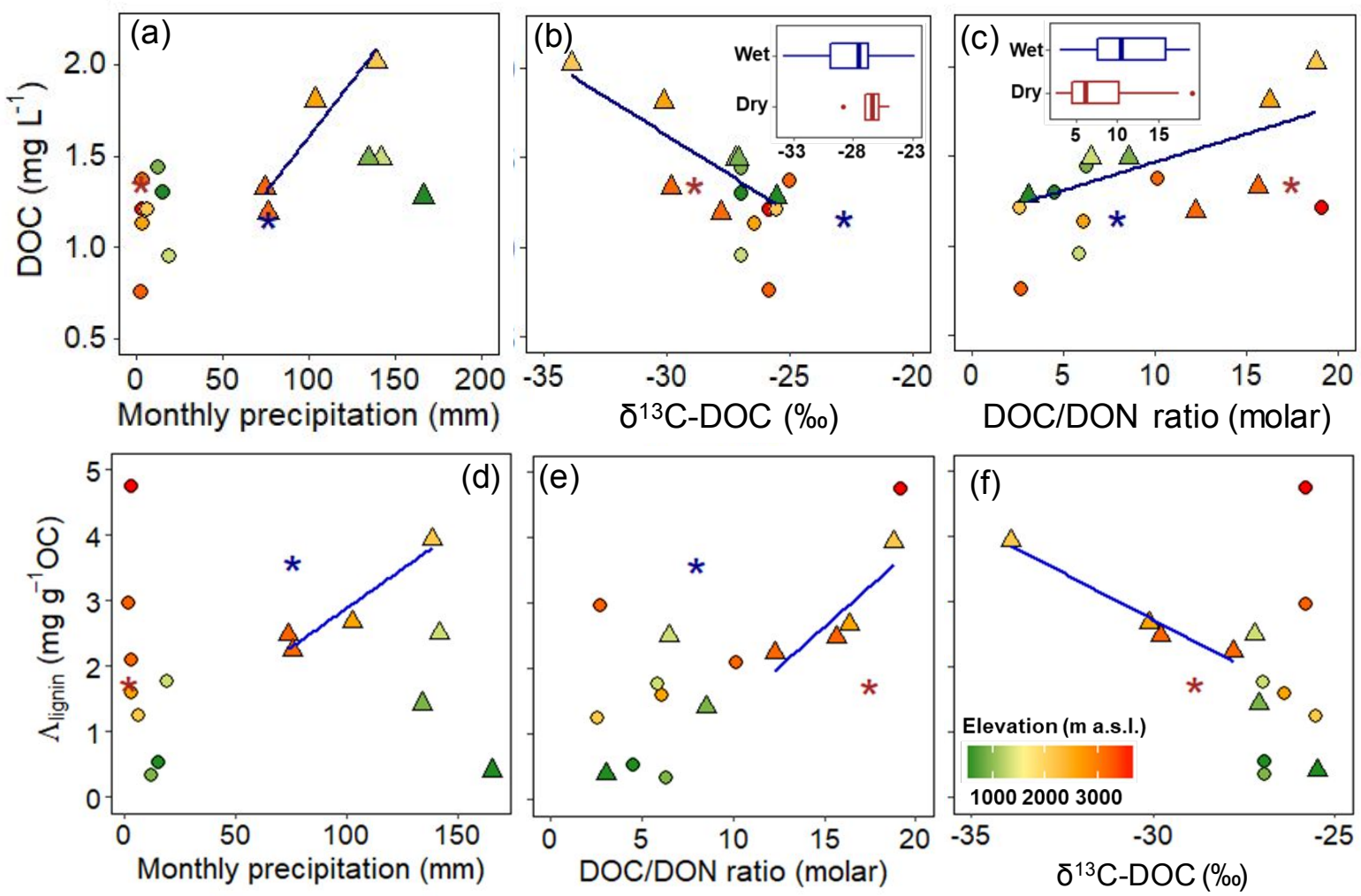

Figure S4. Relationships between dissolved organic carbon (DOC) and monthly precipitation (a), between DOC and $\delta^{13} \mathrm{C}$ values of dissolved organic carbon $\left(\delta^{13} \mathrm{C}-\mathrm{DOC}\right.$; b ), between DOC and DOC-to-dissolved organic nitrogen ratios (DOC/DON) ratio (c), between organic carbonnormalized content $\left(\Lambda_{\text {lignin }}\right)$ and monthly precipitation (d), between $\Lambda_{\text {lignin }}$ and $\delta^{13} \mathrm{C}$-DOC (e), and between $\Lambda_{\text {lignin }}$ and DOC/DON ratios (f), respectively, in the dissolved organic matter (DOM) of the Lancang River. Dots, triangles and asterisks represent dry-mainstem, wetmainstem and tributary samples, respectively. Dry- and wet-season samples are in red and blue, respectively. Color-bar in (f) applied to panels (a), (b), (c), (d), and (e) as well. The blue lines in panels (b), (c), (d), (e), and (f) correspond to the linear regression of data in the upper mainstem (blue dots outside reservoirs; $p<0.05$ ) in wet season, respectively. Black line in (a) represents the linear regression of data in both seasons $(p<0.05)$. The inserted plots in (b) and (c) are the comparison of $\delta^{13} \mathrm{C}-\mathrm{DOC}$ and DOC/DON ratios between the dry and wet season (paired t-test), respectively. Solid line in the box marks the median of each dataset. The upper and lower ends of boxes denote the 0.25 and 0.75 percentiles, respectively. Dots denote outliners. 

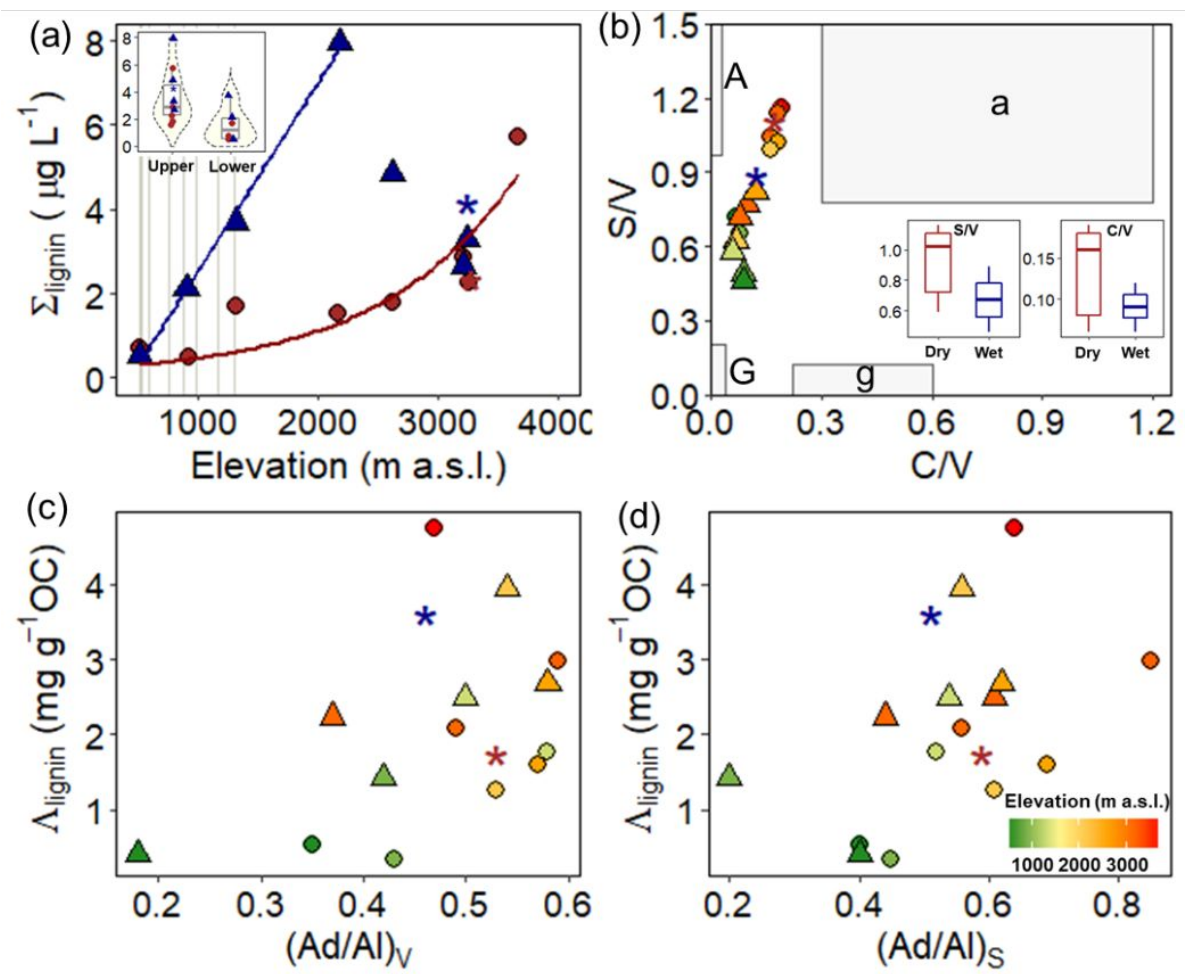

Figure S5. Changes in the lignin phenol concentration $\left(\Sigma_{\text {lignin }}\right.$; a) in the Lancang River; relationships between the syringyl to vanillyl phenol ratio $(\mathrm{S} / \mathrm{V})$ and cinnamyl to vanillyl phenol ratio $(\mathrm{C} / \mathrm{V} ; \mathrm{b})$; correlation of organic carbon-normalized content of lignin phenols $\left(\Lambda_{\text {lignin }}\right)$ with vanillic acid to vanillin ratio $(\mathrm{Ad} / \mathrm{Al})_{\mathrm{V}}(\mathrm{c})$, syringic acid to syringaldehyde ratio $(\mathrm{Ad} / \mathrm{Al})_{\mathrm{S}}(\mathrm{d})$. Color-bar in (d) applied to (b) and (c) as well. The inserted violin plots in (a) compare $\Sigma_{\text {lignin }}$ between the upper and lower reach (one-way ANOVA, $p<0.05$ ). Solid line marks the median of each dataset with the upper and lower ends denoting the 0.25 and 0.75 percentiles, respectively. Dots denote raw data. The blue line in (a) represent linear correlation in the lower reach, and the red line represent log regression of data in the dry season $(p<0.05)$. The shaded regions in (b) represent traditionally defined regions for angiosperm woods (A), angiosperm non-woody tissues (a), gymnosperm woods $(\mathrm{G})$, and gymnosperm non-woody tissues $(\mathrm{g})^{3}$. Other symbols are defined in Figure $\mathrm{S} 1$. 


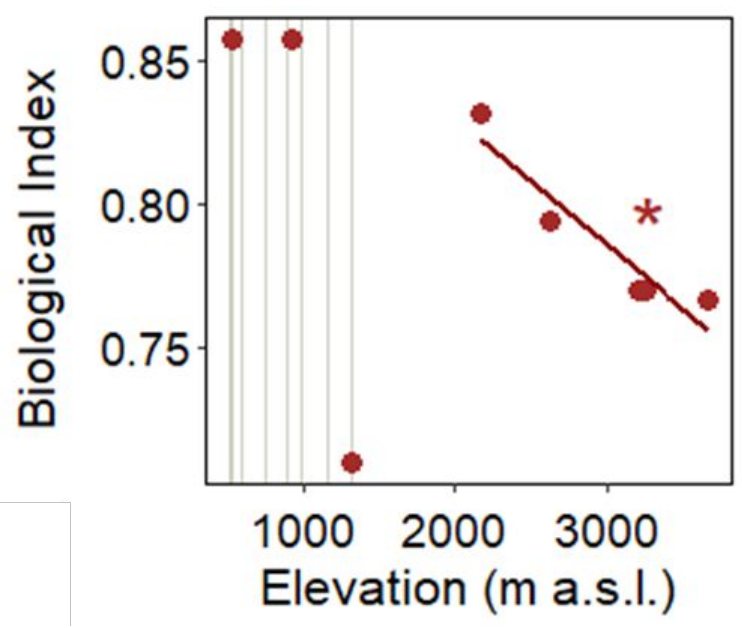

Figure S6. Changes in the biological index (BIX) of dissolved organic matter calculated based on fluorescence measurement in the dry season. Vertical gray lines represent location of hydropower stations. The red line represent the linear regression of parameter with elevation $(p<0.05)$. 


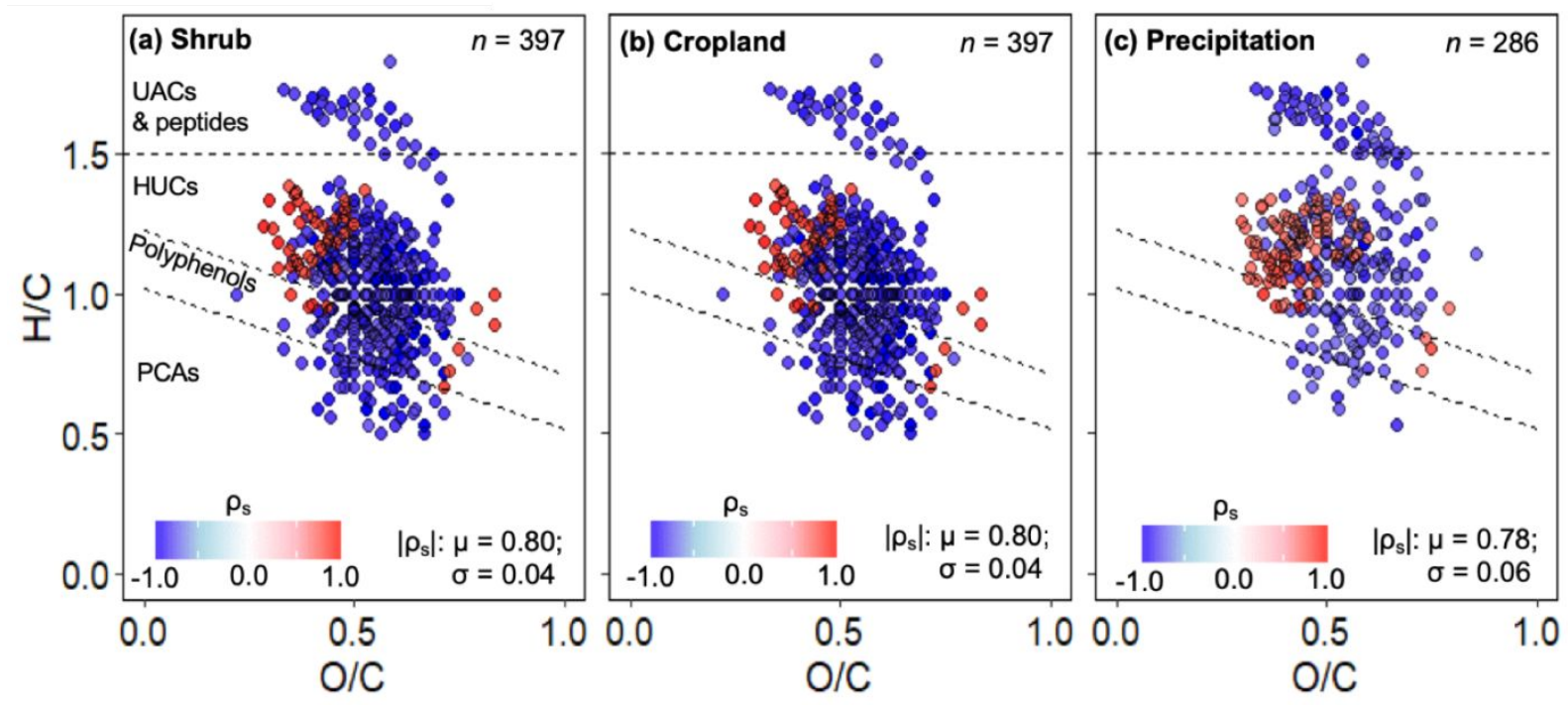

Figure S7. The van Krevelen diagrams showing variations in the relative intensity of molecular formulas for the dry-season dissolved organic matter with changing shrub coverage (a), cropland coverage (b), and monthly precipitation (c), respectively. Color gradients represent Spearman correlation coefficient $\left(\rho_{\mathrm{s}}\right)$ between the relative intensity of each molecular formula and the given environmental variable. Only formulas that are significantly correlated with the given environmental variable $(p<0.05)$ are shown. $\left|\rho_{\mathrm{s}}\right|$ refers to the mean $(\mu)$ and standard deviation $(\delta)$ of the absolute value of $\rho_{\mathrm{s}}$ for all retained formulas in each panel. Compound groups include polycyclic aromatics (PCAs; modified aromaticity index $\left(\mathrm{AI}_{\mathrm{mod}}\right) \geq$ $0.67)$, polyphenols $\left(0.5 \leq \mathrm{AI}_{\text {mod }}<0.67\right)$, low-oxygen highly unsaturated compounds (lowoxygen $\mathrm{HUCs}$; $\mathrm{AI}_{\bmod }<0.5, \mathrm{H} / \mathrm{C}<1.5$ and $\mathrm{O} / \mathrm{C}<0.5$ ), high-oxygen highly unsaturated compounds (high-oxygen $\mathrm{HUCs} ; \mathrm{AI}_{\bmod }<0.5, \mathrm{H} / \mathrm{C}<1.5$ and $\mathrm{O} / \mathrm{C} \geq 0.5$ ), unsaturated aliphatic compounds (UACs; $1.5 \leq \mathrm{H} / \mathrm{C}<2.0, \mathrm{~N}=0$ ), and peptides $(1.5 \leq \mathrm{H} / \mathrm{C}<2.0, \mathrm{~N}>0)$ ). Compound category labels for delineation in (a) also apply to delineated regions in (b) and (c). Lines separating compound categories on van Krevelen diagrams are for visualization only and exact categorization may slightly differ. 

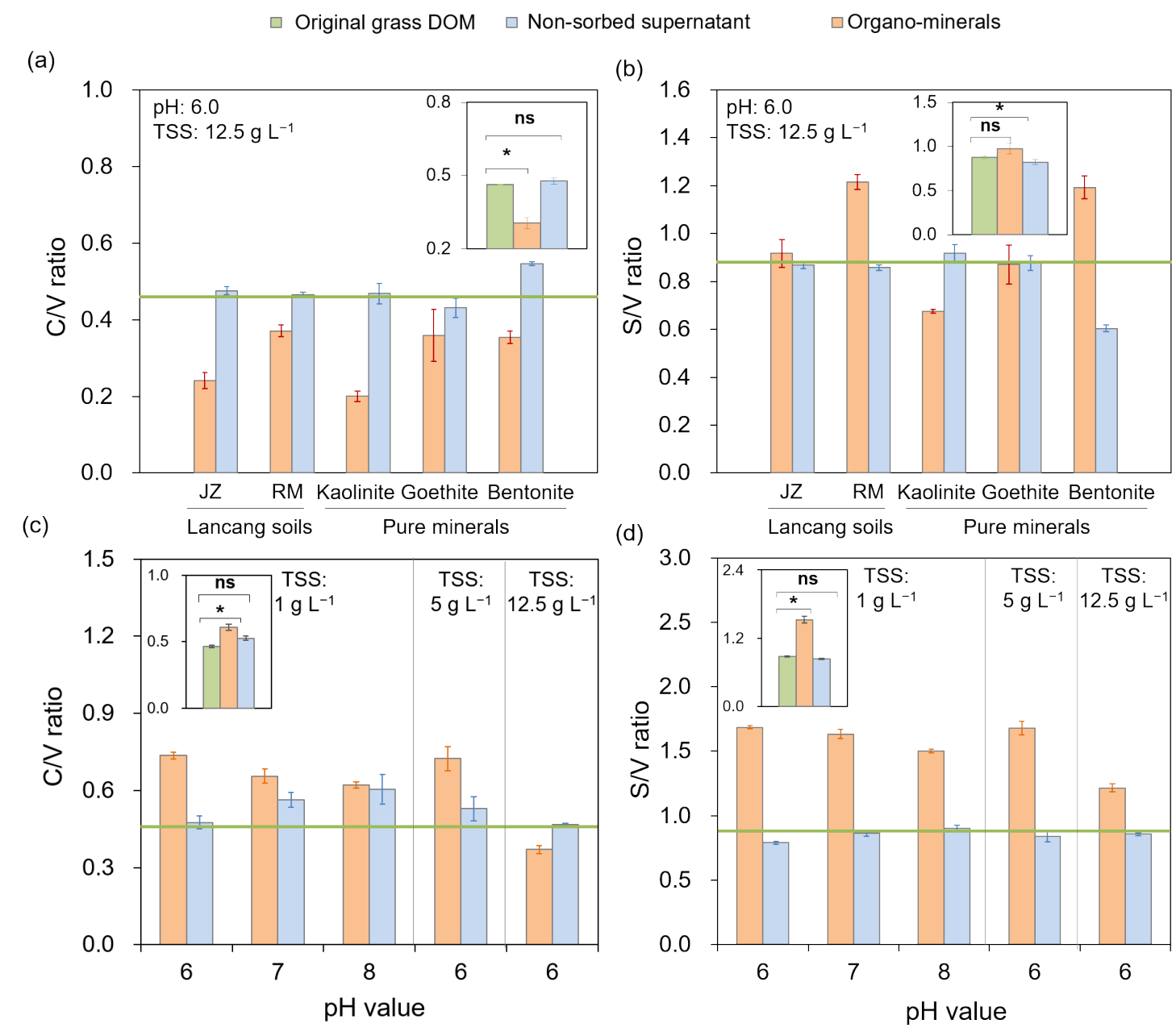

(d)

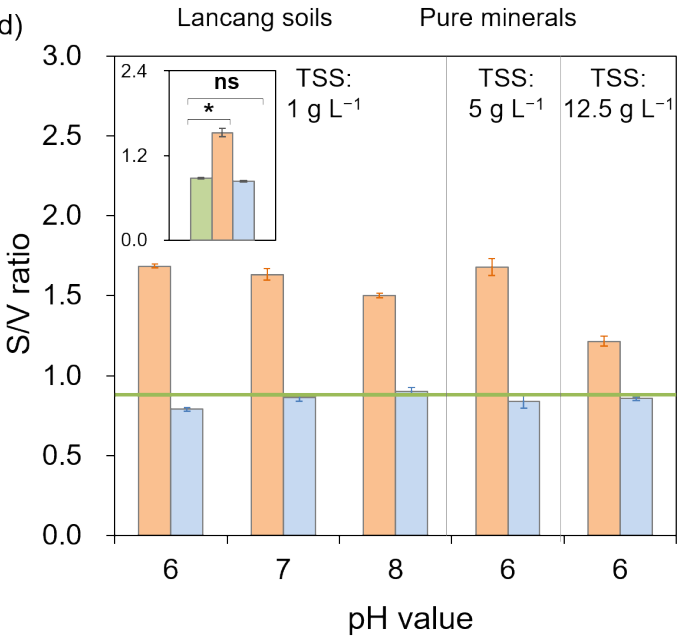

Figure S8. Changes in the ratios of cinnamyl to vanillyl phenols $(\mathrm{C} / \mathrm{V})$ and syringyl to vanillyl phenols ratio $(\mathrm{S} / \mathrm{V})$ after the sorption of grass-derived dissolved organic matter (DOM) to different minerals at $\mathrm{pH} 6.0$ and total suspended sediment (TSS) of $12.5 \mathrm{~g} \mathrm{~L}^{-1}(\mathrm{a}-\mathrm{b})$, and to $\mathrm{RM}$ soil mineral under different $\mathrm{pH}$ and TSS conditions (c-d). Green lines represent mean ligninphenol $\mathrm{C} / \mathrm{V}$ and $\mathrm{S} / \mathrm{V}$ ratios of original grass DOM, respectively. Error bars represent standard error of mean ( $n=3$ except in inserts). The inserts in $(a-b)$ show mean values for all minerals $(\mathrm{n}=15)$ and grass extracts $(\mathrm{n}=3)$; the inserts in $(\mathrm{c}-\mathrm{d})$ show mean values for all $\mathrm{pH}$ and suspended solid concentrations $(n=15)$ and grass extracts $(n=3)$; ns, not significant; * indicates significant difference (one-way ANOVA, $p<0.05$ ). 


\section{References}

(1) Goñi, M. A.; Montgomery, S. Alkaline $\mathrm{CuO}$ oxidation with a microwave digestion system: Lignin analyses of geochemical samples. Anal. Chem. 2000, 72 (14), 3116-3121.

(2) Dittmar, T.; Koch, B.; Hertkorn, N.; Kattner, G. A simple and efficient method for the solid-phase extraction of dissolved organic matter (SPE-DOM) from seawater. Limnol. Oceanogr. Meth. 2008, 6 (6), 230-235.

(3) Hernes, P. J.; Robinson, A. C.; Aufdenkampe, A. K. Fractionation of lignin during leaching and sorption and implications for organic matter "freshness". Geophys. Res. Lett. 2007, 34 (17), L17401.

(4) Hernes, P. J.; Kaiser, K.; Dyda, R. Y.; Cerli, C. Molecular trickery in soil organic matter: hidden lignin. Environ. Sci. Technol. 2013, 47 (16), 9077-9085.

(5) Zhai, H. Study on the river ecological integrity under the threat of hydropower development in LRGR. Ph.D. dissertation, Beijing Normal University, Beijing. (in Chinese), 2009.

(6) Huang, J.; Fu, K.; He, D. Analysis on the Characteristics of Sediments in the Middle and Lower Parts of the Lancang River. Journal of Sichuan University (Engineering Science Edition) 2010, 42 (03), 112-120. (in Chinese). 